\title{
Modulation of Fragmental Charge Transfer via Hydrogen Bonds. Direct Measurement of Electronic Contributions ${ }^{\dagger}$
}

\author{
Roie Yerushalmi, ${ }^{\S}$ Alexander Brandis, ${ }^{\S}$ Varda Rosenbach-Belkin, ${ }^{\S}$ Kim K. Baldridge, $\$$ and \\ Avigdor Scherz*,\$
}

Department of Plant Sciences, The Weizmann Institute of Science, 76100 Rehovot, Israel, and Organic Chemistry Institute, University of Zürich, Zürich CH-8057, Switzerland

Received: May 27, 2005; In Final Form: July 18, 2005

\begin{abstract}
Hydrogen bonds play an important role in an overwhelming variety of fields from biology to surface and supramolecular chemistry. The term "hydrogen bond" refers to a wide range of interactions with various covalent and polar contributions. In particular, hydrogen bonds have an important role in the folding and packing of peptides and nucleic acids. Recent studies also point to the importance of hydrogen bonding in the context of second-shell interactions, in metal binding and selectivity in metalloproteins, and in controlling the dynamics of membrane proteins. In this study, we demonstrate and quantify the modulation of fragmental charge transfer from hydrogen-bonded ligands to a metal center, by employing our recently introduced molecular potentiometer. The molecular details that affect this type of fragmental charge transfer are presented and a path for transferring chemical information is demonstrated. We found that $\mathrm{H}$-bond interactions in the extended positions of axial ligands provide an effective means of modulating the amount of fragmental charge transfer to a metal center, thereby dramatically influencing the electronic properties of the ligand, the binding affinity, and the binding of additional ligands. The magnitude of fragmental charge-transfer modulation induced by a single ligand-solvent $\mathrm{H}$-bond interaction is comparable to those induced by covalent substitution, although $\mathrm{H}$-bond enthalpy is only on the order of several kilojoules per mole. Importantly, we find a significant change in the ligand electronic properties, even for weak $\mathrm{C}-\mathrm{H} \cdots \mathrm{O}=\mathrm{C}$ H-bond formation, where the bond enthalpy is substantially lower than for conventional H-bond interactions. The excess fragmental charge transferred to the metal center, deduced from the spectroscopic measurements, correlates well with the computationally determined values. Our findings underscore the importance of second-shell interactions in the active sites of enzymes, beyond the structural and electrostatic importance that is widely recognized today.
\end{abstract}

\section{Introduction}

Hydrogen bonds (H-bonds) are among the most diverse interactions encountered in and between molecules in the solid, liquid, and gas phases. Although the interaction energy is typically on the order of $12-30 \mathrm{~kJ} / \mathrm{mol}$ for classical H-bonds, the impact of such interactions on the chemical and biophysical behavior of many systems is cardinal. Often, the accumulation of a few moderate, or even weak H-bond interactions can collectively affect the chemical reactivity and properties dramatically. ${ }^{1}$ There is an overwhelming number of publications aimed at understanding various aspects and roles of $\mathrm{H}$-bonding in biological as well as synthetic systems. Accordingly, studies involving $\mathrm{H}$-bond interactions span many fields and approaches. For example, in some studies, phenomenological statistical analyses of structures are performed to obtain structural parameters and classes of $\mathrm{H}$-bonds. Other studies focus on the biophysical activity of enzymes while studying specific mechanistic functions of a particular $\mathrm{H}$-bond found in the active site or with single solvent molecules. ${ }^{2-12}$ Although such studies have greatly advanced the understanding of the H-bond phenomena and the role $\mathrm{H}$-bonding plays in affecting the kinetics and thermodynamics of proteins, experimental limitations still

\footnotetext{
† Part of the special issue "Donald G. Truhlar Festschrift".

* To whom correspondence may be addressed. E-mail: avigdor.scherz@ weizmann.ac.il.

$\S$ Weizmann Institute of Science.

$\doteqdot$ University of Zürich.
}

obscure the direct elucidation of the electronic details of such interactions for nonordered phases at the molecular level. Difficulties emerge from both the intrinsic properties of such interactions and the fact that the associated energy may be only a few kilojoules per mole. Thus, the natural complexity found in systems with H-bond interactions, combined with the lack of an experimental observable for measuring the results of such bonding at the electronic level, limits the quantitative study and understanding of mechanistic details. Some of the valuable experimental approaches currently used for measuring the electronic perturbation related to $\mathrm{H}$-bonding include $\mathrm{X}$-ray electron density deformation maps, IR frequency shifts used to deduce H-bond enthalpy and charge transfer, and NMR chemical shifts. ${ }^{13-16}$ Among other important functions, H-bonding has been shown to directly affect the properties and reactivity of redox centers in both biological and nonbiological catalysis. ${ }^{17-24}$ It has been suggested that the underlying mechanisms in many H-bond-mediated reactions involve modification of the redox center's electronic density. Hence, quantification of the electronic changes induced by $\mathrm{H}$-bond formation with direct observation of the fragmental charge transfer involving ligands and metal redox centers should both improve our understanding of reaction mechanisms and progress the design of new catalysts. We have recently introduced and developed the "molecular potentiometer", a molecular probe that enables measurement of fragmental charge transfer between ligands and transition metals. ${ }^{25,26}$ Here, we expand this methodology to obtain a direct 
experimental estimate of the electronic effects induced at the metal center following the formation of coordinated ligand molecules that can form additional $\mathrm{H}$-bond interactions with the solvent molecules.

\section{Measurement of Fragmental Charge Transfer Utilizing the Molecular Potentiometer}

A. General Procedure. The molecular potentiometer can be visualized as having two components. One component is the electronic $\pi$ system of the bacteriochlorophyll (BChl), or a modified $\mathrm{BChl}$ derivative. The chromophore frontier molecular orbitals (FMOs) are mainly delocalized over the macrocycle. The second component is a metal atom, chelated at the central core of the macrocycle by $\sigma$ bonding to the four nitrogen atoms and functioning as an exchangeable "probe". To a first-order approximation, the two components are independent of each other, except for electrostatic effects. ${ }^{27,28}$ Alterations in the effective charge as well as in the effective covalent radius of the metal modify the FMOs' energies and the measured transition energies of the $\pi$ system. These observations provide a quantitative means for measuring fragmental charge transfer between the metal and various axial ligands. ${ }^{29} \mathrm{We}$ have previously shown, experimentally and computationally, that fragmental charge flow between $[\mathrm{Ni}]-\mathrm{BChl}$ and various axial ligands can be deduced from the $Q_{x}$ band shift $\left(\triangle E Q_{x}\right)$ as a single experimental observable. ${ }^{25,26}$ This is because the increase in core size is essentially constant when comparing the nonligated low-spin [Ni]-BChl and the various high-spin $(S=1)[\mathrm{Ni}]-\mathrm{BChl} \cdot(\mathbf{m})_{n}$ complexes (where $n=1,2$ and $\mathbf{m}$ is a ligand molecule). ${ }^{25}$ This experimental gauge offers exceptional sensitivity and accuracy with small experimental error limits $\left( \pm 0.005 \mathrm{e}^{-}\right)$, independently verified by comparison with $\mathrm{ab}$ initio results. ${ }^{26}$ Here, we present a generalization of the experimental system, showing accurate measurement of fragmental charge transfer to a metal center induced by additional interactions with the environment, beyond the previously studied metal-ligand binding. The generalized approach for measurement of fragmental charge transfer between a metal center and coordinating ligands $(\mathbf{m})$ capable of forming additional interactions with solvent molecules (s) to form $(\mathbf{m} \cdot \cdot \mathbf{s})$ complexes involves the following steps:

(I) Refinement of the spectroscopic probe to achieve higher chemical stability and better resolved spectroscopic data.

(II) Validation of the spectral linear response $\left(\triangle E Q_{x}\right.$ in energy units) of the refined spectroscopic probe to fragmental charge transfer between the metal and coordinating ligands by comparison of $\triangle E Q_{x}$ values to those of the [Ni]-BChl derivative.

(III) Calibration of the spectroscopic response to charge units by comparing spectroscopic and computationally derived fragmental charge-transfer values for a calibration set of complexes where no specific ligand-solvent interaction is present.

(IV) Measurement of the spectroscopic response to binding of ligand molecules that incorporate functional groups capable of forming additional ligand-solvent interactions with their surroundings, such as H-bond, halogen bonding, or other chemical interactions.

(V) Derivation of the residual fragmental charge-transfer quantities $\left(\Delta Q_{\text {residual }}\right)$ transferred to the metal center because of the specific ligand-solvent interactions studied (e.g. H-bond, in the present study)

B. Application to H-Bond-Induced Fragmental Charge Transfer. (I) Following the above general procedure, the [Ni]PyroBPheid-Me derivative was selected as the spectroscopic probe (Scheme 1). We used this derivative because it is
SCHEME 1: (a) [Ni]-BChl $a$ Molecule $(\mathrm{R}=$ Phytyl) and (b) the $[\mathrm{Ni}]-$ PyroBPheid-Me Derivative
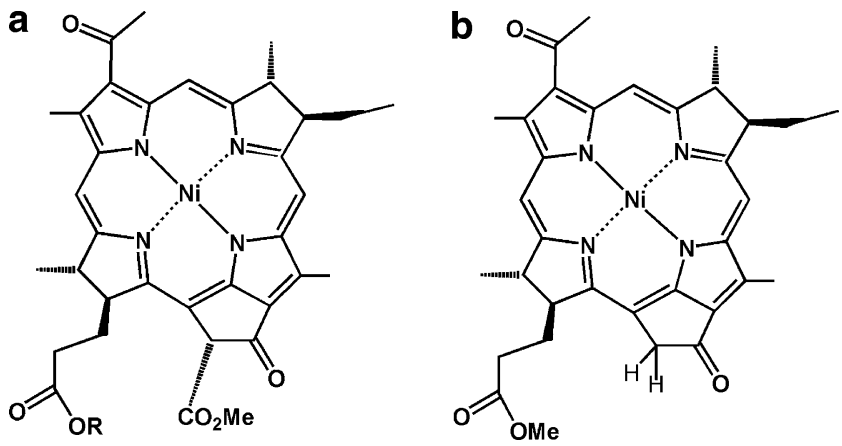

significantly easier to prepare and handle compared to the previously studied $[\mathrm{Ni}]-\mathrm{BChl}$ derivative. ${ }^{30}$ In particular, replacement of the $\mathrm{BChl}$ carbomethoxy side-group by a proton provides chemical stability and spectroscopic homogeneity by preventing spontaneous epimerization and allomerization, typical for the BChl derivative at this site. ${ }^{31,32}$ As a result, the spectroscopic transitions for the pyrolyzed macrocycle are narrower, providing superior spectroscopic response. The improved accuracy has enabled measurements of small fragmental charge-transfers with a sensitivity of $\pm 0.003 \mathrm{e}^{-}$. Additionally, compatibility with a wide range of solvents is made possible.

(II) The spectroscopic response of the [Ni]-PyroBPheidMe derivative to axial ligand binding was compared with that of the $[\mathrm{Ni}]-\mathrm{BChl}$ in order to verify that the linear response $\mathrm{e}^{26}$ to fragmental charge transfer is preserved.

(III) Calibration for the solvent systems studied was performed in two steps:

(i) $\triangle E Q_{x}$ values were measured for a set of coordinating ligands having no $\mathrm{H}$-bond-forming groups $(\mathbf{m}=\mathbf{6}-\mathbf{1 2})$ (Scheme 3 ). In particular, we explored the effect of ligand-solvent H-bond formation (Scheme 2) by systematically varying the nucleophilic character of the solvent molecules in the series $\mathbf{s}=\mathbf{1 - 4}$, as well as by using a nonpolar solvent such as toluene $(\mathrm{s}=\mathbf{5})$.

(ii) These $\Delta E Q_{x}$ values were used as a single experimental observable to correlate with calculated fragmental chargetransfer values ( $\Delta N_{\mathrm{Lig}}^{\mathrm{NPA}}$ ) using the simple equation: ${ }^{25}$

$$
\Delta E Q_{x}=\alpha_{\text {solv }} \Delta N_{\mathrm{Lig}}^{\mathrm{NPA}}+\beta_{\text {solv }}
$$

Where $\Delta N_{\mathrm{Lig}}^{\mathrm{NPA}}$ is the calculated fragmental charge transfer using the NPA atomic charge scheme for the fully optimized structures using HDFT methods, and $\alpha_{\text {solv }}\left(\mathrm{eV} / \mathrm{e}^{-}\right)$and $\beta_{\text {solv }}(\mathrm{eV})$ are the linear fit parameters (Table 3). As noted, the values of the linear fit parameters, $\alpha_{\text {solv }}$ and $\beta_{\text {solv }}$, depend on computational methodology, the level of theory, the basis set, and the atomic charge scheme. ${ }^{25,26}$ On the experimental side, these values depend on the solvent properties.

(IV) $\Delta E Q_{x}$ values were measured for a set of coordinating ligands having functional groups capable of forming $\mathrm{H}$-bond interactions in the various solvent systems $(\mathbf{s}=\mathbf{1 - 4})$.

(V) The H-bond-induced fragmental charge transfer to the metal center was derived using the following analysis. The predicted $Q_{x}$ band shift ( $\triangle E Q_{x}^{\text {pred }}$ ) for each H-bonding ligand in the absence of ligand-solvent interaction was derived using eq 2 :

$$
\Delta E Q_{x}^{\mathrm{pred}}=\alpha_{\mathrm{solv}} \Delta N_{\mathrm{Lig}}^{\mathrm{NPA}}+\beta_{\text {solv }}
$$


SCHEME 2: [Ni]-PyroBPheid-Me with Axial Ligand (m) Having H-bond Interaction with the Surrounding Solvent Molecules (s) at Peripheral Ligand Positions ${ }^{a}$

a)

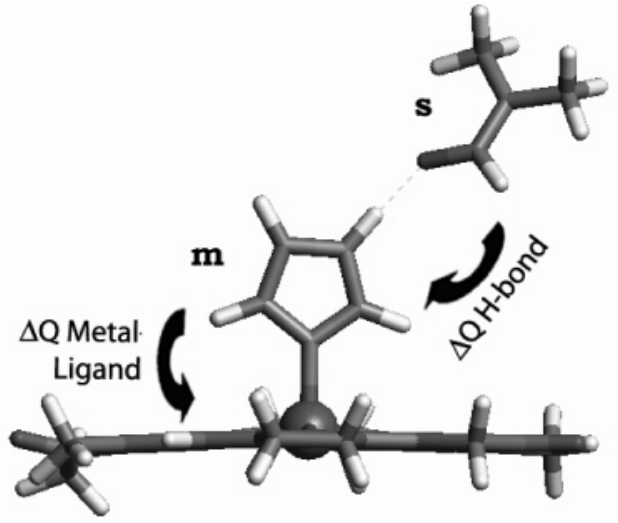

b)

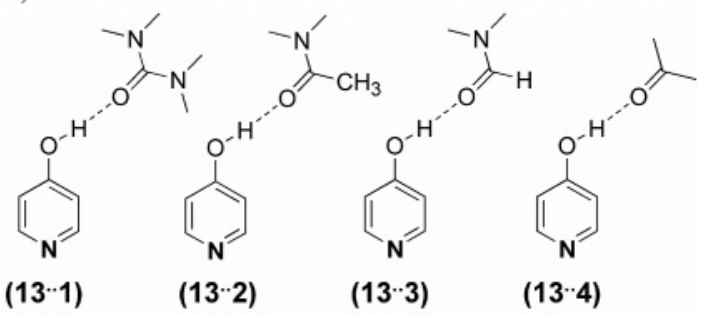

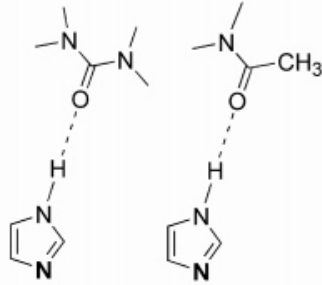

$(17 \cdots 1)$

$(17 \times 2)$

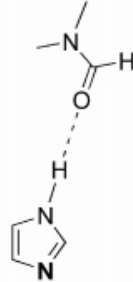

$(17 \cdots 3)$

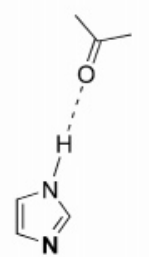

$(17 \cdots 4)$
${ }^{a}$ The side view of the $\left([\mathrm{Ni}]-\right.$ PyroBPheid-Me $\left.\cdot(\mathbf{1 7} \cdot \cdot \mathbf{3})_{1}\right)$ complex is shown. (b) Examples of H-bond pairs studied: 4-hydroxypyridine (13) and imidazole (17), ligands with 1,1,3,3-tetramethylurea (1), $\mathrm{N}, \mathrm{N}$ dimethylacetamide (2), $N, N$-dimethylformamide (3), and acetone (4).

where $\Delta N_{\mathrm{Lig}}^{\mathrm{NPA}}$ was calculated for the [Ni]-PyroBPheid$\mathrm{Me} \cdot(\mathbf{m})_{n}$ complex as previously described, with no H-bond interaction. The experimentally measured $Q_{x}$ band shift values $\left(\triangle E Q_{x}^{\mathrm{obs}}\right)$ obtained from each spectroscopic component were compared to the predicted $Q_{x}$ band shift values $\left(\triangle E Q_{x}^{\text {pred }}\right)$ for the corresponding complexes to yield $\Delta Q_{\text {residual }}$ values (Table 4).

$$
\Delta Q_{\text {residual }}=\left(\Delta E Q_{x}^{\mathrm{obs}}-\Delta E Q_{x}^{\mathrm{pred}}\right) \alpha_{\text {solv }}^{-1}
$$

The $\Delta Q_{\text {residual }}$ values obtained from this procedure correspond to the difference between the calculated and measured systems, namely the ligand-solvent $\mathrm{H}$-bond interaction. To validate the above procedure we also calculated $\Delta N_{\mathrm{Lig}}^{\mathrm{NPA}}$ values for the corresponding $[\mathrm{Ni}]-$ PyroBPheid $-\mathrm{Me} \cdot(\mathbf{m} \cdot \cdot \mathbf{s})_{n}$ complexes (for $\mathbf{s}=\mathbf{3}$ ), where $\mathbf{m} \cdot \mathbf{s}$ represents ligand-solvent $\mathrm{H}$-bond interaction included in the optimized structure and the subsequent charge analysis, for the set of ligand molecules capable of forming $\mathrm{H}$-bond interactions. In this case, $\Delta Q_{\text {residual values obtained by }}$ eq 3 should be close to zero (within experimental error limits), since the calculated system includes the additional $\mathrm{H}$-bond interaction and subsequent fragmental charge transfer.
SCHEME 3: Solvent and Ligand Molecules Used in the Present Study and the Abbreviations Used Solvent Molecules (1-5), Ligand Molecules with No H-bond Donor Groups (6-12), with - OH Groups (13-16), with $\mathrm{N}-\mathrm{H}$ (17), and $\mathrm{N}-\mathrm{CH}_{3}$ (18) Groups<smiles>CN(C)C(=O)N(C)C</smiles>

(1)<smiles>c1ccncc1</smiles>

(6)<smiles>CC(C)(C)c1ccncc1</smiles><smiles>Oc1ccncc1</smiles>

(13)
(10)

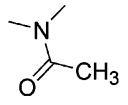

(2)<smiles>Cc1ccncc1</smiles>

(7)<smiles>c1ccc(-c2ccncc2)cc1</smiles>

(11)<smiles>CN(C)C=O</smiles>

(3)<smiles>Cc1cncc(C)c1</smiles>

(8)<smiles>CC(C)=O</smiles>

(4)<smiles>Cc1ccccc1</smiles>

(5)<smiles>CCc1ccncc1</smiles>

(9)<smiles>COc1ccncc1</smiles>

(12)

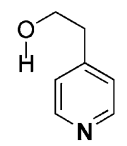

(16)<smiles>Oc1cccnc1</smiles>

(14)<smiles>c1c[nH]cn1</smiles>

(17)<smiles>OCc1ccncc1</smiles>

(15)<smiles>Cn1ccnc1</smiles>

(18)

The method described here provides information that is not influenced by the intricate interactions in the bulk liquid, often encountered in the study of H-bonding solvents. Furthermore, the calibration procedure allows for the cancellation of systematic errors that may result from incomplete computational treatment of the electronic interactions as long as this incompleteness is consistent for the studied set of complexes. Using this molecular tool, we report here for the first time the direct experimental measurement of the amount of fragmental charge transferred to the transition metal center upon $\mathrm{H}$-bond formation at the periphery of a conjugated ligand molecule. Remarkably, we are able to report accurate charge-density contributions in a solvent environment with no need for modifications such as crystallization or other perturbations that may alter the studied systems. Specifically, we find that the axial ligand's conjugated electronic system mediates the $\mathrm{H}$-bond-induced charge transfer to the metal center. We show that separation of the H-bond donor group from the $\pi$ system, via short alkyl chains (e.g., $-\mathrm{CH}_{2}-,-\mathrm{CH}_{2}-\mathrm{CH}_{2}-$ ), blocks the associated fragmental charge transfer. Collectively, our observations provide a quantification of the electronic effect of solvent H-bonding to metalbound ligands. Such interactions "fine-tune" the electronic density, with the potential to substantially modulate coordination properties and, therefore, the catalytic activity of metal centers.

\section{Materials and Methods}

Synthesis. Pyrobacteriopheophorbide (PyroBPheid). BChl a was isolated from Rhodovulum sulfidophilum by standard 
methods ${ }^{33}$ and used as a starting material for preparing the corresponding BPheid. Then, PyroBPheid was prepared by reacting BPheid $(50 \mathrm{mg})$ in pyridine $(5 \mathrm{~mL})$ at $135-145^{\circ} \mathrm{C}$ in a sealed ampule for $3 \mathrm{~h} .{ }^{34 \mathrm{a}}$ The mixture was evaporated, redissolved in chloroform, and washed with acidified water $(\mathrm{HCl}, \mathrm{pH}$ 4.5). Finally, the organic layer was dried and evaporated.

ESI-MS (-): $551.57(\mathrm{M}-1) \mathrm{m} / \mathrm{z}$.

PyroBPheid methyl ester (PyroBPheid-Me) was obtained quantitatively by treatment of PyroBPheid with an ethereal solution of diazomethane. ${ }^{34 \mathrm{~b}}$

${ }^{1} \mathrm{H} \mathrm{NMR}\left(400 \mathrm{MHz}, \mathrm{CDCl}_{3}\right) \delta: 9.02(5-\mathrm{H}, \mathrm{s}), 8.50(10-\mathrm{H}$, s), $8.45(20-\mathrm{H}, \mathrm{s}), 5.13$ and $4.96\left(13^{2}-\mathrm{CH}_{2}, \mathrm{dd}, J_{\mathrm{AB}}=19.8 \mathrm{~Hz}\right)$, 4.32 (7,18-H, m), 4.16 (8-H, m) and 4.06 (17-H, m), 3.65 (174-

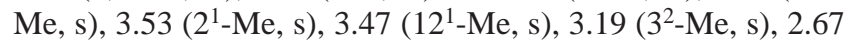
and 2.26 (each $1 \mathrm{H}, 17^{1}-\mathrm{CH}_{2}, \mathrm{~m}$ ), 2.54 and 2.33 (each $1 \mathrm{H}, 17^{2}-$ $\left.\mathrm{CH}_{2}, \mathrm{~m}\right), 2.39$ and 2.12 (each $\left.1 \mathrm{H}, 8^{1}-\mathrm{CH}_{2}, \mathrm{~m}\right), 1.82\left(7^{1}-\mathrm{Me}, \mathrm{d}\right.$, $J=7.2 \mathrm{~Hz}), 1.76\left(18^{1}-\mathrm{Me}, \mathrm{d}, J=7.3 \mathrm{~Hz}\right), 1.13\left(8^{2}-\mathrm{Me}, \mathrm{t}, J=\right.$ $7.3 \mathrm{~Hz}$ ), 0.37 and -1.02 (each NH, s). ${ }^{13} \mathrm{C}$ NMR (chloroformd) $\delta: 100.6(10), 98.6(5), 97.3(20), 56.4(17), 53.2\left(17^{4}\right), 52.6$ (8), and $50.9(18), 50.1(7), 49.1\left(13^{2}\right), 34.8\left(3^{2}\right), 32.2\left(17^{2}\right)$, $31.6\left(8^{1}\right), 31.3\left(17^{1}\right), 24.5\left(7^{1}\right), 24.4\left(18^{1}\right), 15.6\left(2^{1}\right), 13.0\left(12^{1}\right)$, $12.2\left(8^{2}\right)$.

[Ni]-PyroBPheid-Me, One-Pot Transmetalation of PyroBPheid Methyl Ester. PyroBPheid methyl ester was reacted with cadmium acetate $(40 \mathrm{mg})$ in $\mathrm{DMF}(4 \mathrm{~mL})$ at $110{ }^{\circ} \mathrm{C}$ for 30 min. Then, anhydrous nickel chloride $(45 \mathrm{mg}$ ) was added to the reaction mixture, resulting in almost an immediate conversion into the nickel complex. The progress of cadmium and nickel insertion was monitored spectroscopically by following the $Q_{x}$ bands $(522,588$, and $540 \mathrm{~nm})$ and $Q_{y}$ bands $(753,771$, and $789 \mathrm{~nm}$ ) for PyroBPheid-Me, [Cd]-PyroBPheid-Me, and [Ni]-PyroBPheid-Me in the reaction mixture, respectively. At the completion of $\mathrm{Ni}$ incorporation, the solvent was evaporated and the pigment redissolved in chloroform and purified on silica column $\left(\mathrm{CHCl}_{3}\right)$. Additional silica column chromatography using $\mathrm{CHCl}_{3}-n$-hexane $(2: 1 \mathrm{vol})$ separated the product from small impurities of nonmetalated PyroBPheid methyl ester to yield $20 \mathrm{mg}$ of [Ni]-PyroBPheid methyl ester (73\%). ESI-MS $(-)$ : 622.81 and $645.73\left([\mathrm{M}]^{+}\right.$and $[\mathrm{M}-\mathrm{H}+\mathrm{Na}]^{+}$for $\left.{ }^{58} \mathrm{Ni}\right)$, with a characteristic isotopic pattern of $\mathrm{Ni}$.

UV-Vis-NIR in $\mathrm{CH}_{2} \mathrm{Cl}_{2}$, (nm, RI): (338.6, 0.7), (392.2, $0.4),(537.3,0.2),(785.6,1.0)$.

Spectroscopic Titrations. Absorption spectra were recorded on a CARY 5 UV-visible-NIR spectrophotometer. Typically, $2 \mathrm{~mL}$ of a $5 \mu \mathrm{M}[\mathrm{Ni}]-$ PyroBPheid-Me solution in dry solvent was placed in a $10 \mathrm{~mm}$ optical pathway quartz cuvette that was sealed with a Teflon-coated rubber septum. Ligands were injected through the septum with a gastight microliter syringe. Spectra at different ligand concentrations were recorded during each titration. Factor analysis was employed to resolve the spectroscopic components of non-, mono-, and bi-ligated species as previously described. ${ }^{27,35}$ Liquids were used as received (anhydrous), or dried over activated molecular sieves (Sigma) according to Burfield et al. ${ }^{36,37}$ Solid ligand molecules were of analytical grade from Aldrich, Sigma, and Acros Organics, and used as received in a freshly prepared solution.

Computational Methods. Metal Complexes. We have recently studied several computational methodologies for calculating $[\mathrm{Ni}]-\mathrm{BChl}$ in various coordination states. ${ }^{26}$ Based on our findings, we used the hybrid density functional (HDFT) B3P86 with the Stuttgart and Dresden (SDD) basis set for calculating structural and electronic properties for the nickel-containing complexes. The SDD basis set, with double- $\zeta$ quality in the valence and "valence- 1 " shells, incorporates a single $f$ function for $\mathrm{Ni}$, and the double- $\xi$ valence basis set of Dunning on the first- and second-row atoms. The RECP for Ni contains the Darwin and mass-velocity contributions of Stuttgart and Dresden $(\mathrm{Ni},(8 \mathrm{~s} 7 \mathrm{p} 6 \mathrm{~d} 1 \mathrm{f}) \rightarrow[6 \mathrm{~s} 5 \mathrm{p} 3 \mathrm{~d} 1 \mathrm{f}])$.

Here we study the electronic character of axially ligated chromophore $\left([\mathrm{Ni}]-\right.$ PyroBPheid-Me $\left.(\mathbf{m})_{n}\right)$ interacting with ligand molecules capable of forming specific $\mathrm{H}$-bonds with the surrounding solvent molecules $\left([\mathrm{Ni}]-\mathrm{PyroBPheid}-\mathrm{Me} \cdot(\mathbf{m} \cdot \cdot \mathbf{s})_{n}\right)$ through functional groups at their periphery (Scheme 2). The detailed QM treatment of the large molecular system described here was made possible using the highly efficient RECP in combination with HDFT. Notably, RECPs have been found to be computationally very efficient and reliable approaches for handling relativistic effects, which must be accounted for in complexes involving nickel. ${ }^{38}$ In particular, the combination of HDFT and RECP was found useful for evaluating differences between non-, mono-, and bi-axially ligated structures interacting with various solvent molecules. The conformational analyses of the molecular systems described here, including structural and orbital arrangements as well as property calculations, were carried out using a variety of computational techniques as implemented in GAUSSIAN03. ${ }^{39}$

Each stationary point was uniquely characterized by calculating and diagonalizing the matrix of energy second derivatives (Hessian) to determine the number of imaginary frequencies $(0=$ minima; $1=$ transition state $)$. In cases where structures with multiple imaginary frequencies were located, the corresponding vibrational eigenvector modes were followed in order to locate the global minimum. Zero-point vibrational energy (ZPE) corrections, derived from the corresponding Hessian calculations, were included in all reported energetics.

As discussed in previous work, we employed the NPA atomic charge analysis method for charge analysis on optimized structures. ${ }^{40}$ Computational charge-transfer values $\left(\Delta N_{\mathrm{Lig}}\right)$ for the $[\mathrm{Ni}]-$ PyroBPheid-Me $(\mathbf{m})_{n}$ and $[\mathrm{Ni}]-$ PyroBPheid-Me $(\mathbf{m} \cdot \mathbf{s})_{n}$ complexes were obtained by a summation of the atomic charge values for the atoms of the axial ligand fragment $(\mathbf{m})_{n}$ and ligand-solvent pairs $(\mathbf{m} \cdot \mathbf{s})_{n}$ of the corresponding monoor bi-ligated complexes.

Ligand-Solvent Pairs $(m \cdot s)$. The optimized structures and properties of ligand-solvent H-bond pairs $(\mathbf{1 3} \cdot \mathbf{1}),(\mathbf{1 3} \cdot \mathbf{2})$, $(\mathbf{1 3} \cdot \mathbf{3}),(\mathbf{1 3} \cdot \mathbf{4}),(\mathbf{1 7} \cdot \mathbf{1}),(\mathbf{1 7} \cdot \mathbf{2}),(\mathbf{1 7} \cdot \mathbf{3}),(\mathbf{1 7} \cdot \mathbf{4}),(\mathbf{8} \cdot \mathbf{3})$, and $(\mathbf{1 8} \cdot \mathbf{3})$ were calculated using HDFT techniques. ${ }^{41}$ In particular, we employed Becke's three-parameter hybrid exchange functional ${ }^{42}$ with the widely used Lee-Yang-Parr (LYP) gradientcorrected correlation functional. ${ }^{43}$ The combination of this functional with augmented basis sets has been determined to provide a relatively accurate estimate for conventional $\mathrm{H}$-bond interactions.

For all $(\mathbf{m} \cdot \mathbf{s})$ ligand-solvent pair calculations, the augmented correlation-consistent (aug-cc) basis sets were used (B3LYP/ aug-cc-pVDZ). The H-bond enthalpies include ZPE corrections and thermal enthalpy corrections derived from the Hessian analysis at the B3LYP/aug-cc-pVDZ level ( $\Delta H$ values, Table 2 ). Basis set superposition error (BSSE) was derived using the Boys-Bernardi counterpoise scheme. ${ }^{44}$

Ionization potentials (IP) and electron affinities (EA) were calculated and used for obtaining the change in electronegativity $(\Delta \chi)$ and hardness $(\Delta \eta)$ of the respective ligand-solvent pairs $(\mathbf{m} \cdot \mathbf{s})$ relative to the corresponding free ligand molecule $(\mathbf{m})$. For the weak H-bond pairs, $(\mathbf{8} \cdot \mathbf{3})$ and $(\mathbf{1 8} \cdot \mathbf{3})$, a set of singlepoint computations employing second-order Møller-Plesset 
TABLE 1: Calculated Changes in Interaction Energies

\begin{tabular}{|c|c|c|}
\hline \multirow[b]{2}{*}{ complex } & \multicolumn{2}{|c|}{ B3P86/SDD } \\
\hline & $\begin{array}{c}-\Delta \Delta E_{H B} \\
\text { hydrogen bond } \\
(\mathrm{kJ} / \mathrm{mol})\end{array}$ & $\begin{array}{c}-\Delta \Delta E_{M L} \\
\text { metal-ligand bond } \\
(\mathrm{kJ} / \mathrm{mol})\end{array}$ \\
\hline $\begin{array}{l}{[\mathrm{Ni}]-\text { PyroBPheid-Me• }} \\
(\mathbf{1 3} \cdot \mathbf{3})_{1}\end{array}$ & 10.0 & 10.5 \\
\hline $\begin{array}{l}{[\mathrm{Ni}]-\text { PyroBPheid-Me• }} \\
(\mathbf{1 3} \cdot \mathbf{3})_{\mathbf{2}}\end{array}$ & 1.7 & -1.7 \\
\hline $\begin{array}{l}{[\mathrm{Ni}]-\text { PyroBPheid-Me }} \\
(\mathbf{1 4} \cdot \mathbf{3})_{1}\end{array}$ & 10.5 & 11.7 \\
\hline $\begin{array}{l}{[\mathrm{Ni}]-\text { PyroBPheid-Me• }} \\
(\mathbf{1 4} \cdot \mathbf{3})_{\mathbf{2}}\end{array}$ & 4.6 & 1.7 \\
\hline $\begin{array}{l}{[\mathrm{Ni}]-\text { PyroBPheid-Me• }} \\
(\mathbf{1 7} \cdot \mathbf{3})_{\mathbf{1}}\end{array}$ & 16.3 & 15.9 \\
\hline $\begin{array}{l}{[\mathrm{Ni}]-\text { PyroBPheid-Me• }} \\
(\mathbf{1 7} \cdot \mathbf{3})_{2}\end{array}$ & 9.2 & 5.9 \\
\hline $\begin{array}{l}{[\mathrm{Ni}]-\text { PyroBPheid-Me• }} \\
(\mathbf{1 8} \cdot \mathbf{3})_{1}\end{array}$ & 5.9 & 6.7 \\
\hline $\begin{array}{l}{[\mathrm{Ni}]-\text { PyroBPheid-Me• }} \\
(\mathbf{1 8} \cdot \mathbf{3})_{\mathbf{2}}\end{array}$ & 2.1 & 0.4 \\
\hline $\begin{array}{l}{[\mathrm{Ni}]-\text { PyroBPheid-Me• }} \\
(\mathbf{8} \cdot 3)_{1}\end{array}$ & 5.4 & 6.7 \\
\hline $\begin{array}{l}{[\mathrm{Ni}]-\text { PyroBPheid-Me• }} \\
(\mathbf{8} \cdot \mathbf{3})_{2}\end{array}$ & 2.1 & -0.8 \\
\hline
\end{tabular}

perturbation theory (MP2) at the same reference geometry was performed (MP2/aug-cc-pVDZ//B3LYP/aug-cc-pVDZ).

\section{Computational Results}

$[\mathrm{Ni}]-$ PyroBPheid-Me•(m) $)_{n}$ and $[\mathrm{Ni}]-$ PyroBPheid-Me• $(\mathbf{m} \cdot \mathbf{s})_{n}$ Complexes. Full geometry optimization and Hessian calculations were performed for 38 complexes of the types $[\mathrm{Ni}]-$ PyroBPheid-Me $(\mathbf{m})_{n}$ and $[\mathrm{Ni}]-$ PyroBPheid-Me $(\mathbf{m} \cdot \mathbf{s})_{n}$. The complexes calculated contain typically $\sim 100$ atoms or more, including the nickel atom. As has been shown, the HDFT level of theory used (B3P86/SDD) accurately provides the electronic effects and trends of the systems studied. Although this level of theory would not be satisfactory for reporting absolute values of the H-bond energies, the method serves well for comparison of their relative values and energetics. For several of the weak interactions we show the effects of (MP2), a known improvement over HDFT. We are also currently investigating further the use of ongoing MP2 parallelization strategies of the computational chemistry package, GAMESS, for this purpose. For calculating the changes in $\mathrm{H}$-bond energies and metalligand binding energies in this work, we considered the energetic differences between the non-ligated ligand-solvent pairs $(\mathbf{m} \cdot \mathbf{s})$, and the corresponding bond energies of the [Ni]-PyroBPheid$\mathrm{Me} \cdot(\mathbf{m} \cdot \mathbf{s})_{n}$ complexes. Thus, we consider only the calculated differences in $\mathrm{H}$-bond and metal-ligand bond energies at the level of theory (B3P86/SDD) described in the Materials and Methods section. Table 1 presents changes in $\mathrm{H}$-bond interaction energy $\left(\Delta \Delta E_{\mathrm{HB}}\right)$ calculated by comparing the H-bond energy for $[\mathrm{Ni}]-$ PyroBPheid-Me $\cdot(\mathbf{m} \cdot \mathbf{s})_{n}$ and the corresponding $(\mathbf{m} \cdot \mathbf{s})$ complexes. Changes in metal-ligand interaction energy $\left(\Delta \Delta E_{\mathrm{ML}}\right)$ given in Table 1 were calculated by comparing the metal-ligand bond energy for $[\mathrm{Ni}]-\mathrm{PyroBPheid}-\mathrm{Me} \cdot(\mathbf{m} \cdot \mathbf{s})_{n}$ and the corresponding $[\mathrm{Ni}]-\mathrm{PyroBPheid}-\mathrm{Me} \cdot(\mathbf{m})_{n}$ complexes. The calculated fragmental charge-transfer values $\left(\Delta N_{\mathrm{Lig}}\right)$ for the metal complexes are presented in Table 4.

Calculation of the Electronic Properties of $(\mathrm{m} \cdot \mathrm{s})$ LigandSolvent Complexes. Data from these calculations are shown in Table 2.

\section{Experimental Results}

Fragmental Charge Transfer of Ligands with Various Solvent Molecules. Optical absorption spectra were resolved
TABLE 2: Computational Data for H-Bond Donor-Acceptor (Ligand-Solvent) Pairs ${ }^{a}$

\begin{tabular}{|c|c|c|c|c|}
\hline \multirow[b]{2}{*}{ H-bond type } & \multirow[b]{2}{*}{ complex } & \multicolumn{3}{|c|}{ B3LYP/aug $-c c-p V D Z$} \\
\hline & & $\begin{array}{c}-\Delta \mathrm{H} \\
(\mathrm{kJ} / \mathrm{mol})\end{array}$ & $\begin{array}{l}-\Delta \chi \\
(\mathrm{eV})\end{array}$ & $\begin{array}{l}-\Delta \eta \\
(\mathrm{eV})\end{array}$ \\
\hline $\mathrm{O}-\mathrm{H} \cdots \mathrm{O}=\mathrm{C}$ & $(13 \cdot \cdot 1)$ & 31.0 & 0.54 & 0.77 \\
\hline $\mathrm{O}-\mathrm{H} \cdot \cdots \mathrm{O}=\mathrm{C}$ & $(13 \cdot \cdot 2)$ & 25.5 & 0.43 & 0.67 \\
\hline $\mathrm{O}-\mathrm{H} \cdots \mathrm{O}=\mathrm{C}$ & $(13 \cdot \cdot 3)$ & 24.7 & 0.37 & 0.60 \\
\hline $\mathrm{O}-\mathrm{H} \cdots \mathrm{O}=\mathrm{C}$ & $(13 \cdot 4)$ & 21.8 & 0.28 & 0.48 \\
\hline $\mathrm{N}-\mathrm{H} \cdots \mathrm{O}=\mathrm{C}$ & $(17 \cdot \cdot 1)$ & 22.2 & 0.43 & 0.66 \\
\hline $\mathrm{N}-\mathrm{H} \cdot \cdots \mathrm{O}=\mathrm{C}$ & $(17 \cdot \cdot 2)$ & 19.7 & 0.32 & 0.57 \\
\hline $\mathrm{N}-\mathrm{H} \cdots \mathrm{O}=\mathrm{C}$ & $(17 \cdot \cdot 3)$ & 18.4 & 0.27 & 0.51 \\
\hline $\mathrm{N}-\mathrm{H} \cdots \mathrm{O}=\mathrm{C}$ & $(17 \cdot \cdot 4)$ & 14.7 & 0.22 & 0.44 \\
\hline $\mathrm{N}-\mathrm{CH} \cdots \mathrm{O}=\mathrm{C}$ & $(18 \cdot 3)$ & $4.6(11.7)$ & 0.28 & 0.43 \\
\hline $\mathrm{C}-\mathrm{H} \cdot \cdots \mathrm{O}=\mathrm{C}$ & $(8 \cdot \cdot 3)$ & $0.1(5.4)$ & 0.20 & 0.46 \\
\hline
\end{tabular}

${ }^{a}$ The calculated gas-phase $\mathrm{H}$-bond enthalpies $(\Delta \mathrm{H})$, changes in electronegativity $(\Delta \chi)$, and hardness $(\Delta \eta)$ attributed to H-bond formation relative to the corresponding non-interacting ligand molecule are presented. The numbers in parentheses indicate the MP2/aug-cc-pVDZ// B3LYP/aug-cc-pVDZ calculated enthalpy for the weak $(\mathrm{C}-\mathrm{H} \cdots \mathrm{O}=\mathrm{C})$ H-bonds.

TABLE 3: Linear Fit Parameters $\left(\alpha_{\text {solv }}, \beta_{\text {solv }}, R^{2}\right)$ Obtained by Best-Fit Analysis of the Measured $\Delta E Q_{x}$ Values for $[\mathrm{Ni}]-$ PyroBPheid-Me $\cdot(\mathrm{m})_{n}$ Complexes and the Calculated Charge Transfer $\left(\Delta N_{\text {Lig }}\right)$ in Various Solvents ${ }^{a}$

\begin{tabular}{lccccc}
\hline \multicolumn{1}{c}{ solvent } & $\begin{array}{c}\alpha_{\text {solv }} \\
\left(\mathrm{eV}^{*} \mathrm{e}^{-1}\right)\end{array}$ & $\begin{array}{c}\beta_{\text {solv }} \\
(\mathrm{eV})\end{array}$ & $R^{2}$ & STDV & $n$ \\
\hline toluene & 0.9253 & 0.0385 & 0.996 & 0.003 & 13 \\
acetone & 1.0407 & 0.0319 & 0.998 & 0.002 & 13 \\
$N, N$-dimethylformamide & 1.0297 & 0.0361 & 0.994 & 0.004 & 13 \\
$N, N$-dimethylacetamide & 1.0510 & 0.0305 & 0.995 & 0.003 & 13 \\
$1,1,3,3$-tetramethylurea & 0.9895 & 0.0390 & 0.998 & 0.003 & 11
\end{tabular}

${ }^{a}$ The number of data points used for each linear fit $(n)$ and the standard deviation (STDV) from the best-fit values are given.

by applying factor analysis techniques to three spectroscopic components, corresponding to the absorption spectra of the non-, mono-, and bi-axially ligated complexes as previously described. ${ }^{27,35} \Delta E Q_{x}$ values obtained from the spectroscopic measurements with solvents $\mathbf{1 - 5}$ are presented in Table 4 . The $\Delta E Q_{x}$ values measured for various ligand molecules were found to maintain almost perfect linearity $\left(R^{2}=0.99\right)$ by comparing the corresponding $\Delta E Q_{x}$ values measured for [Ni]PyroBPheid-Me $\cdot(\mathbf{m})_{n}$ and $[\mathrm{Ni}]-\mathrm{BChl} \cdot(\mathbf{m})_{n}$ derivatives, where m corresponds to the axial ligand molecule, and $n=1,2$ for the mono- and bi-ligated complexes, respectively. Once the above-mentioned linear response was established for the [Ni]PyroBPheid-Me derivative, we correlated $\triangle E Q_{x}$ values with calculated fragmental charge-transfer values, $\Delta N_{\mathrm{Lig}}^{\mathrm{NPA}}$, obtained by applying a uniform computational treatment for all [Ni]PyroBPheid-Me•(m) $)_{n}$ and $[\mathrm{Ni}]-$ PyroBPheid-Me $(\mathbf{m} \cdot \cdot \mathbf{s})_{n}$ types of structures studied (B3P86/SDD, NPA charge analysis). These correlations yielded $\alpha_{\text {solv }}, \beta_{\text {solv }}$ values (Table 3 ) for ligand molecules 6-12 for each solvent (where solv $=\mathbf{1}-\mathbf{5}$ ). Fits were performed for ligands having no H-bond accepting groups at the solvent environments for calibration. For ligand molecules with no H-bond donor groups, we observed uniform shifts reflected in variations of $\alpha_{\text {solv }}$ and $\beta_{\text {solv }}$ values for the entire data set while maintaining high correlation quality between $\Delta N_{\mathrm{Lig}}^{\mathrm{NPA}}$ and $\Delta E Q_{x}$ values ( $R^{2}$ values, Table 3 ). As such, the parameter fit fully accounts for the observed phenomenon. For

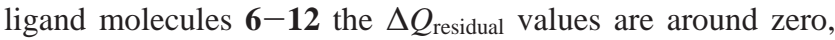
within experimental error limits (Figure $1 \mathrm{a}-\mathrm{g}$ ) with the exception of small positive values for $\mathbf{m}=\mathbf{8}$, (Figure 1c). For the 
TABLE 4: Calculated Fragmental Charge Transfer $\left(\Delta N_{L i g}^{N P A}\right)$, Spectroscopically Measured $Q_{x}$ Band Shifts $\left(\Delta E Q_{x}\right)$, and Residual Fragmental Charge Values $\left(\Delta Q_{\text {residual }}\right)$ for the [Ni]-PyroBPheid-Me•(m) ${ }_{n}$ Complexes

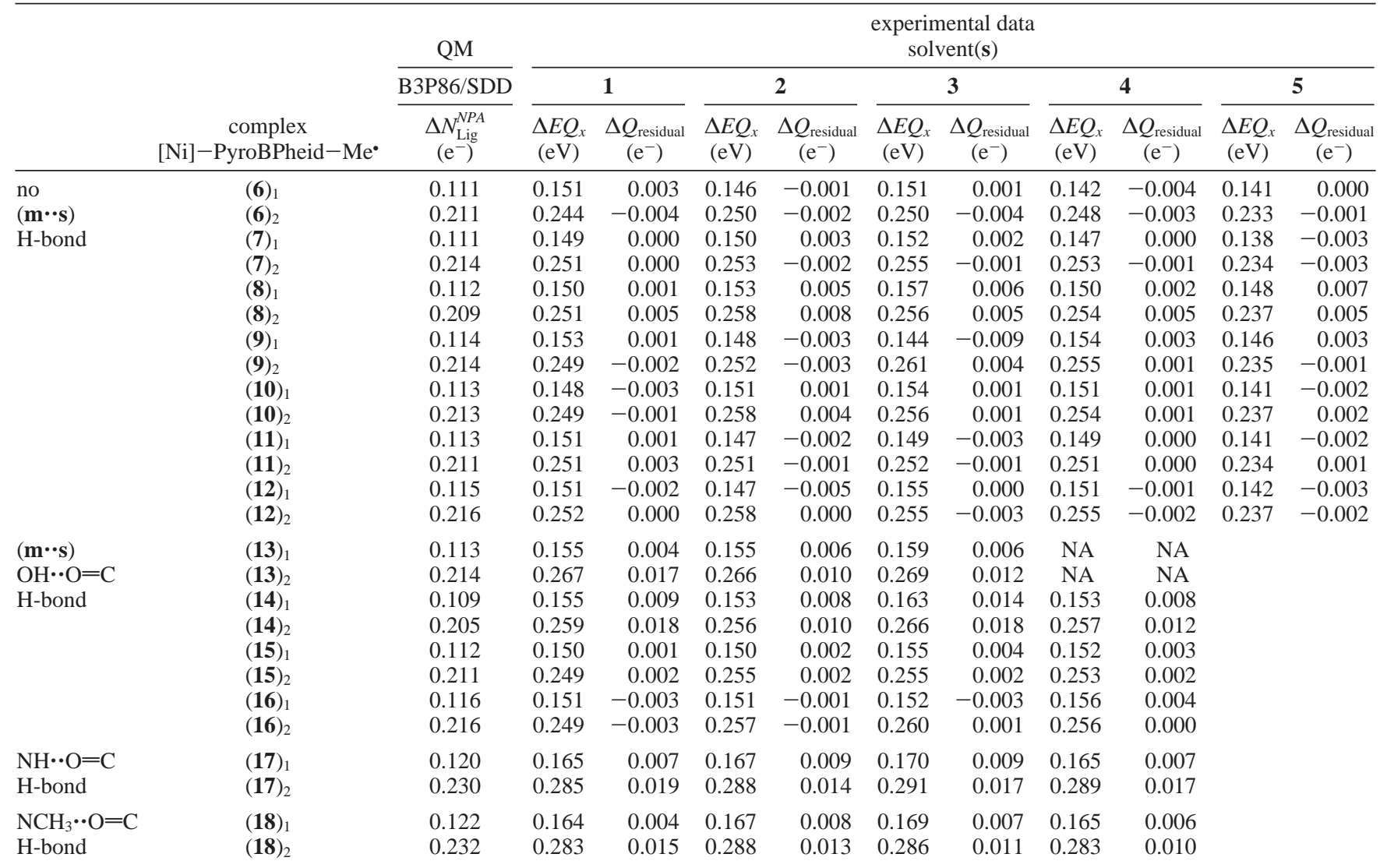

rest of the ligand molecules of the set $\boldsymbol{m}=\mathbf{6}-\mathbf{1 2}, \Delta Q_{\text {residual }}$ values do not indicate significant and consistent deviation throughout the studied solvents, which is potentially indicative of no specific interactions with the solvent molecules. In contrast, for ligand molecules such as 4-hydroxypyridine and imidazole, where there are H-bond interactions between the carbonyl groups of a solvent molecule and the H-bond donor group of the ligand, we observed a substantial red shift of the $Q_{x}$ band. These shifts strongly depend on the ligand molecule as well as on the solvent molecule involved.

Fragmental Charge Transfer of Ligands Possessing HBond Donor $(\mathbf{O}-\mathbf{H})$ with Various Solvent Molecules. Spectroscopic titrations with axial ligands $\mathbf{1 3 - 1 6}$ provided the corresponding non-, mono-, and bi-axially ligated components, as previously described. Unlike the results obtained with ligands 6-12 in the previous section, substantial positive values of $\Delta Q_{\text {residual }}$ were found for ligand molecules 13 and 14 (Figure 2a,b) when the ligand-solvent $\mathrm{H}$-bond interaction was not considered in the calculated structure. This result is consistent with the measurements performed with solvents $\mathbf{1 - 4}$, indicating that the calculated fragmental charge-transfer values $\left(\Delta N_{\mathrm{Lig}}^{\mathrm{NPA}}\right)$ for the corresponding $[\mathrm{Ni}]-\mathrm{PyroBPheid}-\mathrm{Me} \cdot(\mathbf{m})_{n}$ complexes are systematically underestimated compared with the measured band shift values $\left(\Delta E Q_{x}{ }^{\text {obs }}\right)$. Remarkably, the inclusion of $\mathrm{H}$-bond interaction with the solvent molecule at each of the - OH positions resulted in an excellent agreement, as demonstrated for $[\mathrm{Ni}]-$ PyroBPheid-Me $\cdot(\mathbf{1 3} \cdot \mathbf{3})_{2}$, and with a small residual for the $[\mathrm{Ni}]-$ PyroBPheid-Me $(\mathbf{1 4} \cdot \mathbf{3})_{2}$ complex (Figure $2 \mathrm{a}, \mathrm{b}$, respectively). The consistency of the substantially positive values derived from the measurements carried out in four different solvents indicates that these values are not due to arbitrary errors. Therefore, we propose that the consistently positive $\Delta Q_{\text {residual }}$ values obtained for ligand molecules $\mathbf{1 3}$ and $\mathbf{1 4}$ measured with solvents $\mathbf{1 - 4}$ reflect the amount of fragmental charge transfer from the ligand to the metal atom as a result of the H-bonding between the hydroxyl of the axial ligand and the carbonyl of a solvent molecule.

The introduction of an alkyl spacer between the $-\mathrm{OH}$ group and the conjugated $\pi$ system in ligand molecules $\mathbf{1 5}$ and $\mathbf{1 6}$ diminished the $\Delta Q_{\text {residual }}$ values (Figure $2 \mathrm{c}, \mathrm{d}$ ). This result supports our conclusions and indicates that the residual fragmental charge transfer observed for ligand molecules $\mathbf{1 3}$ and $\mathbf{1 4}$ because of $\mathrm{H}$-bonding is mediated specifically via the ligand $\pi$ electronic system.

Fragmental Charge Transfer of Ligands Possessing $\mathbf{H}$ Bond Donor $(\mathbf{N}-\mathbf{H})$ with Various Solvent Molecules. For the imidazole complexes we find substantial positive values of $\Delta Q$ residual for the calculated structures similar to those of the complexes with ligand molecules 13 and 14, where H-bond interaction with the solvent molecules was not considered (Figure 3a). Here again, inclusion of $\mathrm{H}$-bond interactions with solvent molecules at each of the $-\mathrm{NH}$ positions available for each imidazole ligand resulted in excellent agreement between the experimental and computational results, with $\Delta Q_{\text {residual }}$ approaching zero $\left([\mathrm{Ni}]-\right.$ PyroBPheid-Me $(\mathbf{1 7} \cdot \mathbf{3})_{2}$, Figure $\left.3 \mathrm{a}\right)$. Thus, the corresponding positive $\Delta Q_{\text {residual }}$ values are assigned to the amount of fragmental charge transfer as a result of $\mathrm{H}$-bond formation between the $-\mathrm{NH}$ group of the axially ligated molecule and the carbonyl group of a solvent molecule. Notably, we find smaller, but substantial, positive $\Delta Q_{\text {residual }}$ values for the 1-methylimidazole complex as well ([Ni]-PyroBPheid$\mathrm{Me} \cdot(\mathbf{1 8})_{2}$, Figure $\left.3 \mathrm{~b}\right)$. This result indicates that the calculated fragmental charge transfer in the corresponding [Ni]-PyroBPheid-Me $\cdot(\mathbf{m})_{n}$ complexes is underestimated, analogous to our findings with the conventional $\mathrm{H}$-bonding imidazole and the hydroxypyridine ligands. 
a.

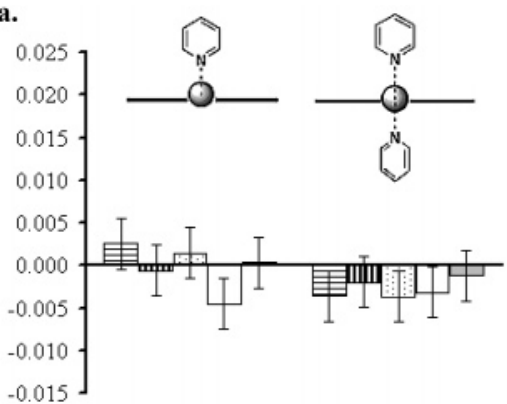

c.

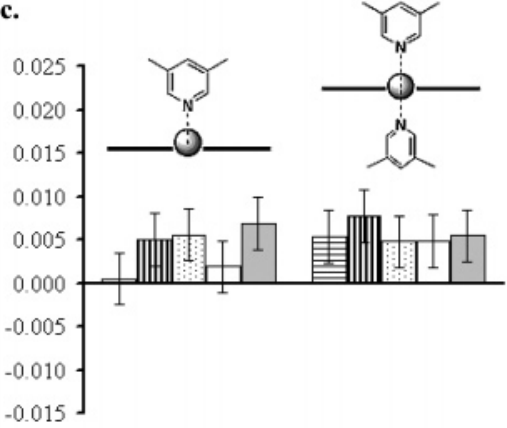

e.

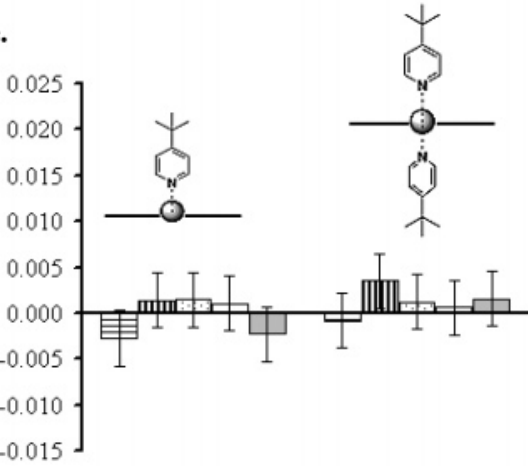

b.

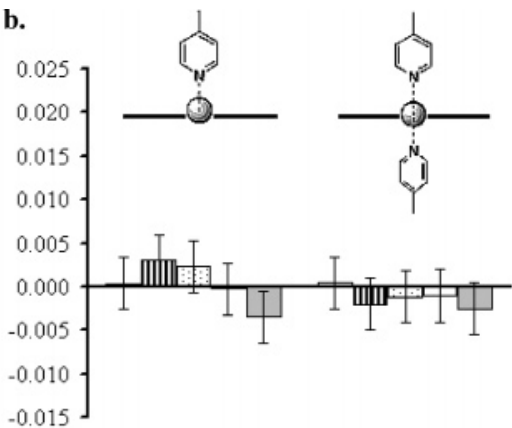

d.
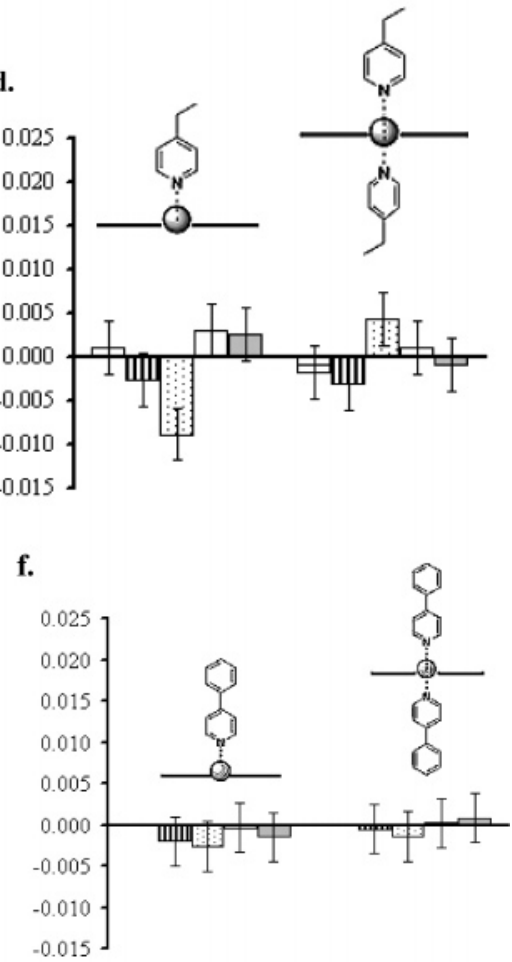

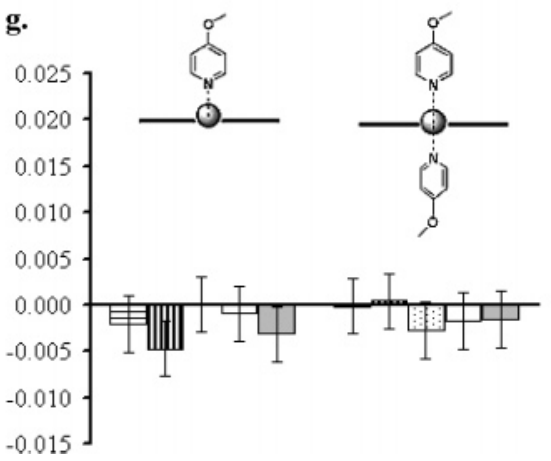

Figure 1. Residual fragmental charge-transfer values $\left(\Delta Q_{\text {residual, }} \mathrm{e}^{-}\right)$for the $[\mathrm{Ni}]-\mathrm{PyroBPheid}-\mathrm{Me} \cdot(\mathbf{m})_{n}$ complexes, where $\mathbf{m}$ represents ligands having no H-bond donor groups. The calculated structures are shown schematically. The spectroscopic data were measured in tetramethylurea (horizontal bars), $N, N$-dimethylacetamide (vertical bars), $N, N$-dimethylformamide (dotted), acetone (white), and toluene (gray).

\section{Discussion}

The procedure presented here yields measurements of the electronic contributions of chemical interactions where chargedensity modulation is mediated to the metal center. This finding expands the scope of the molecular potentiometer beyond the previously demonstrated study of coordination interactions.

For ligand molecules 13, 14, and 17, which can form a conventional $\mathrm{H}$-bond interaction $(-\mathrm{OH},-\mathrm{NH}$ groups) with the surrounding solvent molecules, we found substantially positive values for $\Delta Q_{\text {residual }}$. The $\Delta Q_{\text {residual }}$ values became close to zero, as expected, for the calculated complexes [Ni]-PyroBPheid$\mathrm{Me} \cdot(\mathbf{m} \cdot \mathbf{3})_{2}, \mathbf{m}=\mathbf{1 3}, \mathbf{1 4}$, and $\mathbf{1 7}$ where each of the coordinated ligand molecules forms an $\mathrm{H}$-bond interaction with a DMF solvent molecule. These calculations explicitly consider H-bond interactions between the axially ligated metal complexes and solvent molecules at each of the axial ligands' H-bond donor groups. Overall, the results obtained for the [Ni]-PyroBPheid$\mathrm{Me} \cdot(\mathbf{1 3} \cdot \mathbf{3})_{2}$, [Ni]-PyroBPheid-Me $(\mathbf{1 4} \cdot \mathbf{3})_{2}$, and $[\mathrm{Ni}]-$ PyroBPheid-Me $\cdot(\mathbf{1 7} \cdot \mathbf{3})_{2}$ complexes clearly show that including the two $\mathrm{H}$-bond interactions between the $-\mathrm{OH}$ or $-\mathrm{NH}$ groups of 


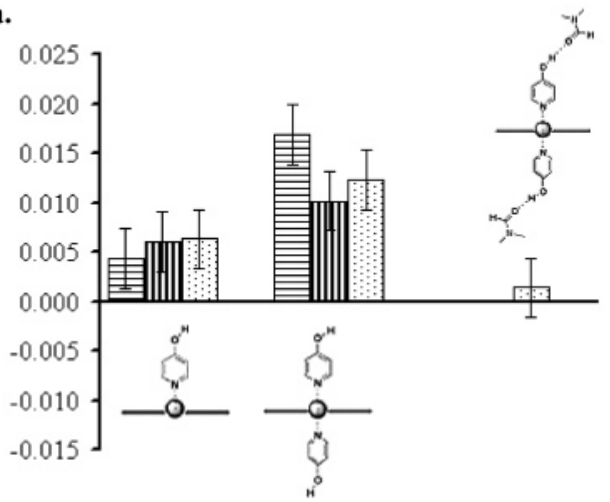

c.

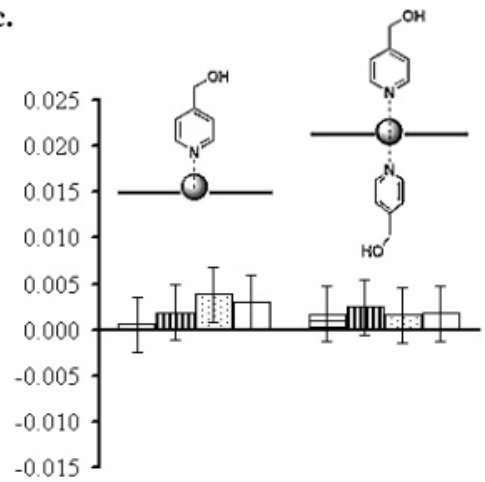

b.

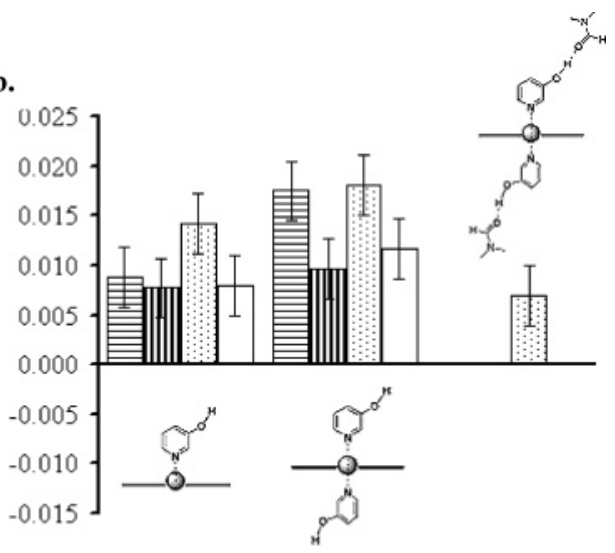

d.

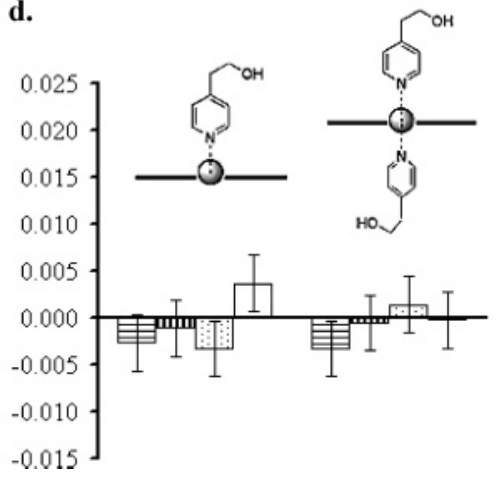

Figure 2. Residual fragmental charge-transfer values $\left(\Delta Q_{\text {residual }}, \mathrm{e}^{-}\right)$for $[\mathrm{Ni}]-\mathrm{PyroBPheid}-\mathrm{Me} \cdot(\mathbf{m})_{n}$ and $[\mathrm{Ni}]-\mathrm{PyroBPheid}-\mathrm{Me} \cdot(\mathbf{m} \cdot \mathbf{s})_{n} \operatorname{complexes}$. Data are presented for ligands having $\mathrm{O}-\mathrm{H}$ H-bond donor groups: 4-hydroxypyridine (a), 3-hydroxypyridine (b), 4-(hydroxymethyl)pyridine (c), and 4-(hydroxyethyl)pyridine (d). The calculated structures are shown schematically. The spectroscopic data were measured in tetramethylurea (horizontal bars), $N, N$-dimethylacetamide (vertical bars), $N, N$-dimethylformamide (dotted), acetone (white), and toluene (gray).The calculated structures used for charge analysis are shown.
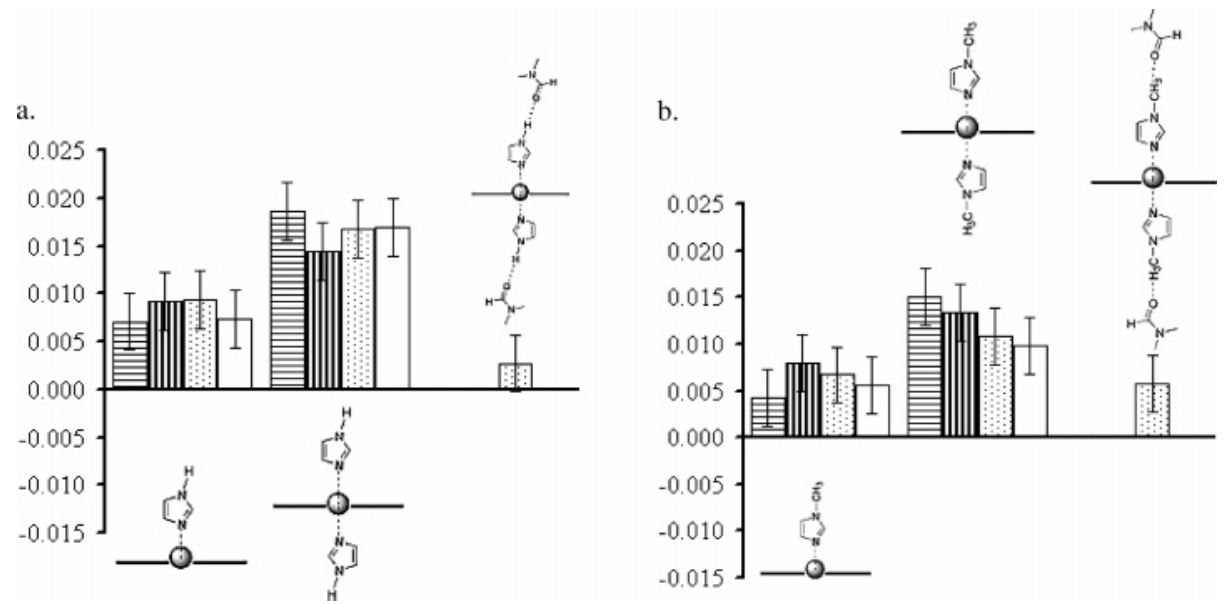

Figure 3. Residual fragmental charge-transfer values $\left(\Delta Q_{\text {residual }}, \mathrm{e}^{-}\right)$for $[\mathrm{Ni}]-\mathrm{PyroBPheid}-\mathrm{Me} \cdot(\mathbf{m})_{n}$ and $[\mathrm{Ni}]-\mathrm{PyroBPheid}-\mathrm{Me} \cdot(\mathbf{m} \cdot \cdot \mathbf{s})_{n} \operatorname{complexes}$. Data are presented for ligands having a $\mathrm{N}-\mathrm{H}$ H-bond donor group for imidazole $\mathbf{1 7}$ (a) and the $\mathrm{C}-\mathrm{H}$ group for 1-methylimidazole $\mathbf{1 8}$ (b). The calculated structures are shown schematically. The spectroscopic data were measured in tetramethylurea (horizontal bars), $N, N$-dimethylacetamide (vertical bars), $N, N$-dimethylformamide (dotted), acetone (white), and toluene (gray).

the ligand molecules and the $\mathrm{C}=\mathrm{O}$ groups of the $\mathrm{DMF}$ solvent molecule is required, and was sufficient for obtaining quantitative agreement with the experimental data, yielding $\Delta Q_{\text {residual }}$ values approaching zero, within error limits (Figures 3a,b, and $4 \mathrm{a}$, respectively). These results provide quantitative agreement of the experimentally measured and computationally derived fragmental charge-transfer values for the H-bond contributions. Namely, $\Delta Q_{\text {residual }}$ values obtained for the complexes are consistent with the excess fragmental charge transfer because of specific H-bond interactions of the two ligand molecules with the surrounding solvent molecules. Introduction of an alkyl
$\left(-\mathrm{CH}_{2}-\right.$, and $-\mathrm{CH}_{2}-\mathrm{CH}_{2}-$ ) spacer between the $-\mathrm{OH}$ group and the ligand's $\pi$ conjugated system (for $\mathbf{m}=\mathbf{1 5}, \mathbf{1 6}$, Figure $3 \mathrm{c}$, d, respectively) resulted in $\Delta Q_{\text {residual }}$ values approaching zero. Hence, the communication between the H-bonding site and the metal center relies on electronic delocalization that is blocked by the introduction of even a single methyl group. These results show the fine details that can be obtained by the procedure demonstrated here, presenting a direct and accurate gauge for following the molecular details of fragmental charge transfer in a solvent environment, caused by metal-ligand coordination interactions, and other interactions such as $\mathrm{H}$-bonds to the 
surrounding, with the end result involving charge-density transfer to the metal center. These findings clearly show that $\Delta Q_{\text {residual }}$ is directly related to the fragmental charge transfer induced by the $\mathrm{H}$-bond formation, $\Delta Q_{\mathrm{H} \text {-bond. Thus, the proce- }}$ dure presented here yields a quantitative measurement of fragmental charge-transfer quantities to the metal center induced by ligand-solvent interactions and mediated or blocked by the ligand electronic structure. The magnitudes of these values range from 0.005 to $0.008 \mathrm{e}^{-}$per single $\mathrm{H}$-bond (Table 4), depending on the axial ligand and solvent, at the levels of theory considered. Notably, these values are comparable in magnitude to the differences obtained by comparing various parasubstituted pyridine derivatives (e.g., $0.006 \mathrm{e}^{-}$per ligand molecule for 4-NMe $\mathrm{N}_{2}$-pyridine vs 4 - $\mathrm{H}$-substituted pyridine). ${ }^{26}$

In particular, the role of $\mathrm{H}$-bond formation by the free $\mathrm{N}-\mathrm{H}$ group of axially ligated imidazole (17) on the coordinated metal electron density and reactivity is highly relevant in many biological systems where histidines are found in the coordination sphere and often interact with additional ligands via H-bond formation. The electronic effects induced by such H-bond interactions to metal-bound ligands may have important consequences for understanding the reactivity of metalloenzymes and redox proteins, where amino acids with $\mathrm{H}$-bond acceptor or donor functionality, such as histidine, cysteine, and tyrosine, are widely found. We found relatively large $\Delta Q_{\text {residual }}$ values, as compared to other H-bond interactions studied here, for the [Ni]-PyroBPheid-Me $(\mathbf{1 7})_{n}$ complex, ranging between 0.007 and $0.009 \mathrm{e}^{-}$per ligand molecule, depending on the solvent. Explicit consideration of the $\mathrm{H}$-bond interaction between the ligand $\mathrm{N}-\mathrm{H}$ and solvent $\mathrm{C}=\mathrm{O}$ groups for the $[\mathrm{Ni}]-$ PyroBPheid-Me $(\mathbf{1 7} \cdot \mathbf{3})_{2}$ complex resulted in excellent agreement of the calculated fragmental charge transfer, $\Delta N_{\mathrm{Lig}}^{\mathrm{NPA}}$, and the spectroscopically measured band shifts, $\Delta E Q_{x}^{\text {obs }}$, yielding a

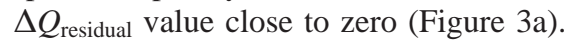

Our findings are in line with previous studies which found that H-bond formation to coordinated imidazole ligands plays an important role in the control of reactivity, ligand binding affinity, redox potentials, and electron-transfer rates. ${ }^{45}$ The data shown here clarifies some of the mechanistic and molecular details involved in protein active site reactivity control by the H-bond-induced fragmental charge transfer. Such mechanisms may be valuable in the design and understanding of catalysis, since $\mathrm{H}$-bond formation and breakage requires moderate investments of free energy, yet results in electronic effects that are comparable to covalent modification of the ligands. Furthermore, since the $\mathrm{H}$-bond formation occurs in the second coordination shell, structural reorganization of the metal's coordination sphere is minimal, resulting in low-energy changes that may be involved.

Interestingly, the amount of fragmental charge transfer because of the $\mathrm{N}-\mathrm{H} \cdots \mathrm{O}=\mathrm{C}$ interactions for the imidazole (17) is substantially larger, compared with the 3- and 4-hydroxypyridines $(\mathbf{1 3}, \mathbf{1 4})$. This result is counter to the order of calculated H-bond energies (Table 2). However, this phenomenon may be explained by the fact that, in the case of imidazole, the $\mathrm{N}-\mathrm{H}$ group is part of the ligand heterocycle, allowing direct electronic communication of the fragmental charge transfer. In the hydroxypyridines, the $-\mathrm{OH}$ group is attached to the heterocycle as a pendant group. This interpretation is consistent with the results for [Ni]-PyroBPheid-Me $(\mathbf{1 5})_{2}$ and $[\mathrm{Ni}]-$ PyroBPheid-Me $(\mathbf{1 6})_{2}$, where the addition of one or two $-\mathrm{CH}_{2}-$ group(s) is sufficient to block the fragmental charge transfer from the H-bond through the ligand electronic system to the metal center. Thus, the amount of H-bond-induced fragmental charge transfer is not necessarily correlated with the bond energy but, rather, with the electronic details of the fragmental charge-transfer pathway. The sensitivity and selectivity of the experimental procedure presented here enables the measurement of electronic contributions because of weak interactions in the solution phase, as demonstrated here for weak $\mathrm{H}$-bonds. We studied the effect of replacing the $\mathrm{N}-\mathrm{H}$ group of imidazole with the $\mathrm{N}-\mathrm{CH}_{3}$ group in 1-methylimidazole ([Ni]PyroBPheid-Me $\cdot(\mathbf{1 8})_{n}$, Figure $\left.3 \mathrm{~b}\right)$. In this case, we found that the $\Delta Q_{\text {residual }}$ values are smaller than in the imidazole $(\mathbf{m}=\mathbf{1 7})$ case. However, these values are substantially and consistently positive for the various solvents investigated, ranging between 0.005 and $0.007 \mathrm{e}^{-}$per $\mathrm{H}$-bond interaction. When the calculation explicitly includes a weak $\mathrm{H}$-bond interaction of the type $\mathrm{N}-\mathrm{CH}_{3} \cdots \mathrm{O}=\mathrm{C}$ between the two 1-methylimidazole ligand molecules and the carbonyl group of two DMF solvent molecule, the $\Delta Q_{\text {residual }}$ value is decreased considerably, from 0.011 to $0.006 \mathrm{e}^{-}$. Thus, after including the weak $\mathrm{H}$-bond interaction between axially ligated 1-methylimidazole molecules (18) and the DMF solvent molecules, we still find an underestimation on the order of $0.003 \mathrm{e}^{-}$per $\mathrm{H}$-bond interaction of the calculated fragmental charge transfer compared with the experimental data. This may result from the difficulty to accurately account for such weak interactions by HDFT methods, such as those presented by the relatively weak $\mathrm{N}-\mathrm{CH}_{3} \cdots \mathrm{O}=\mathrm{C}$ H-bond. Hence, the underestimated residual values may be attributed to the deficiency in HDFT methods for accounting for the dispersion interaction component typical for weak interactions. In particular, it was shown that HDFT methods fail to accurately describe weakly bound clusters and weak H-bonds. ${ }^{46-48}$ The data presented in Table 2 for the weak H-bond pairs $(\mathbf{8} \cdot 3)$ and $(\mathbf{1 8} \cdot \mathbf{3})$ support this finding, where the HDFT calculation yield substantially underestimated bond enthalpies compared to the MP2 values, by 5.3 and $7.1 \mathrm{~kJ} / \mathrm{mol}$, respectively. Interestingly, we also obtained a positive $\Delta Q_{\text {residual }}$ value of $0.0025 \mathrm{e}^{-}$per ligand for 3,5-methyl pyridine ([Ni]-PyroBPheid-Me $(\mathbf{8})_{2}$, Figure 1c). This deviation is accounted for computationally by including two DMF molecules that form a weak $\mathrm{H}$-bond interaction with the two ligands via the ligand's $\mathrm{C}-\mathrm{H}$ group at the para position. This finding is consistent with the calculation for the $(\mathbf{8} \cdot \mathbf{3})$ pair, predicting a slightly negative H-bond enthalpy (Table 2). The H-bond enthalpy is further enhanced in the solvent-ligand metal-bound pair, as found by comparing interaction energies $\left(\Delta \Delta E_{\mathrm{HB}}\right.$, Table 1$)$ for the $(\mathbf{8} \cdot \mathbf{3})$ and $[\mathrm{Ni}]-$ PyroBPheid-Me $(\mathbf{8} \cdot \mathbf{3})_{n}$ complexes, by 5.4 and $2.1 \mathrm{~kJ} / \mathrm{mol}$ for $n=1,2$, respectively. Thus, we find various cases where the amount of fragmental charge transfer induced by a weak $\mathrm{C}-\mathrm{H} \cdots \mathrm{O}=\mathrm{C} \mathrm{H}-$ bond can be measured. Although the absolute value is found to be smaller than that associated with conventional H-bonds, the value is the same order of magnitude and, more importantly, results in profound effects regarding the electronic structure of the ligand molecule.

\section{Concluding Remarks}

We have introduced a spectroscopic tool for direct experimental measurement of fragmental charge transfer to transition metal center induced by $\mathrm{H}$-bond interactions. The approach presented here was shown to provide the means for accurate measurement of charge density contributions induced by $\mathrm{H}-$ bonds in a solvent environment without introducing modifications that may affect the studied systems. Furthermore, the meticulous study of molecular details involved in the communication of chemical information from second-shell interactions to the metal center was demonstrated. Our results highlight 
the particular role of second-shell interactions often found in metalloenzymes in tuning their catalytic reactivity, as found independently in many biological systems. Collectively, our findings demonstrate a substantial modulation of the ligand electronic structure and metal charge density due to ligandsolvent $\mathrm{H}$-bond interactions. The picture revealed here indicates that solvent molecules involved in $\mathrm{H}$-bond interactions may have a significant impact on charge density at the metal center. As such, H-bond interactions, commonly found between the first and second coordination spheres of metal centers in biological systems, are highly significant in fine-tuning the ligand as well as the metal electronic properties. Histidines, widely found in various metalloenzyme catalytic sites, appear to be highly optimized ligands for structuring a versatile metal coordination sphere as well as introducing an efficient and flexible handle via $\mathrm{H}$-bond formation to the ligand - $\mathrm{NH}$ group, as demonstrated for imidazole. Such interactions, either with water, substrate molecules, or the amino acids of a protein, may result in substantial modulation of charge density at the metal center during the catalytic activity. In particular, attention should be given to the presence of water molecules that may impose significant electronic effects on the catalytic metal center by forming specific $\mathrm{H}$-bond interactions. Finally, our data show that weak interactions, such as $\mathrm{C}-\mathrm{H} \cdots \mathrm{O}=\mathrm{C} \mathrm{H}$-bonds, may have a significant impact on the ligand as well as on the metal electronic structure and charge density. Although these interactions are weak in terms of free energy, their impact on charge density is in the same range as found for conventional $\mathrm{H}$-bonds. The combined experimental and computational scheme presented here is expected to offer molecular tools capable of providing quantitative data on the extent of fragmental charge transfer in versatile chemical systems' interactions.

Acknowledgment. This research was supported by a SonderForschungsbereich grant (533), the Willstatter-Avron-Minerva Foundation for Photosynthesis, a SNF grant (21-107979), and the NIH NBCR (RR08605-06). We thank Dr. Leonid Konstantinovski (WIS) for his valuable assistance in the NMR measurements. A.S. is the incumbent of the Yadelle and Robert Sklare Professorial Chair for Biochemistry.

\section{References and Notes}

(1) Srinivasan, R.; Feenstra, J. S.; Park, S. T.; Xu, S. J.; Zewail, A. H. J. Am. Chem. Soc. 2004, 126, 2266-2267.

(2) Bohm, M.; Klebe, G. J. Med. Chem. 2002, 45, 1585-1597.

(3) Fuster, F.; Silvi, B. Theor. Chem. Acc. 2000, 104, 13-21.

(4) Glendening, E. D.; Streitwieser, A. J. Chem. Phys. 1994, 100, 2900-2909.

(5) Steiner, T. Angew. Chem., Int. Ed. 2002, 41, 48-76. 406.

(6) Martin, T. W.; Derewenda, Z. S. Nat. Struct. Biol. 1999, 6, 403-

(7) Barkigia, K. M.; Renner, M. W.; Senge, M. O.; Fajer, J. J. Phy. Chem. B 2004, 108, 2173-2180.

(8) Kienhofer, A.; Kast, P.; Hilvert, D. J. Am. Chem. Soc. 2003, 125, 3206-3207.

(9) Lin, Y. L.; Lim, C. J. Am. Chem. Soc. 2004, 126, 2602-2612.

(10) Yikilmaz, E.; Xie, J.; Brunold, T. C.; Miller, A. F. J. Am. Chem. Soc. 2002, 124, 3482-3483. 6454 .

(11) Schulze, B. G.; Evanseck, J. D. J. Am. Chem. Soc. 1999, 121, 6444-

(12) Senes, A.; Ubarretxena-Belandia, I.; Engelman, D. M. Proc. Natl. Acad. Sci. U.S.A. 2001, 98, 9056-9061.

(13) Arbely, E.; Arkin, I. T. J. Am. Chem. Soc. 2004, 126, 5362-5363.

(14) Arnold, W. D.; Oldfield, E. Abstr. Pap. Am. Chem. Soc. 2000, 220, U202-U202.

(15) Ranganathan, A.; Kulkarni, G. U.; Rao, C. N. R. J. Mol. Struct. 2003, 656, 249-263.
(16) Hagen, K. I.; Schwab, C. M.; Edwards, J. O.; Jones, J. G.; Lawler, R. G.; Sweigart, D. A. J. Am. Chem. Soc. 1988, 110, 7024-7031.

(17) EspinosaGarcia, J.; Corchado, J. C.; Truhlar, D. G. J. Am. Chem. Soc. 1997, 119, 9891-9896.

(18) Sicinska, D.; Truhlar, D. G.; Paneth, P. J. Am. Chem. Soc. 2005, 127, 5414-5422.

(19) Ishikita, H.; Knapp, E. W. J. Am. Chem. Soc. 2004, 126, 80598064 .

(20) Venturoli, G.; Drepper, F.; Williams, J. C.; Allen, J. P.; Lin, X.; Mathis, P. Biophys. J. 1998, 74, 3226-3240.

(21) Johnson, E. T.; Muh, F.; Nabedryk, E.; Williams, J. C.; Allen, J. P.; Lubitz, W.; Breton, J.; Parson, W. W. J. Phys. Chem. B 2002, 106 11859-11869.

(22) Millar, M. Abstr. Pap. Am. Chem. Soc. 2001, 221, U724-U724.

(23) Nabedryk, E.; Breton, J.; Williams, J. C.; Allen, J. P.; Kuhn, M.; Lubitz, W. Spectrochim. Acta a Mol. Biomol. Spectrosc. 1998, 54, 12191230 .

(24) Artz, K.; Williams, J. C.; Allen, J. P.; Lendzian, F.; Rautter, J.; Lubitz, W. Proc. Natl. Acad. Sci. U.S.A. 1997, 94, $13582-13587$.

(25) Yerushalmi, R.; Baldridge, K. K.; Scherz, A. J. Am. Chem. Soc 2003, 125, 12706-12707.

(26) Yerushalmi, R.; Scherz, A.; Baldridge, K. K. J. Am. Chem. Soc. 2004, 126, 5897-5905.

(27) Noy, D.; Yerushalmi, R.; Brumfeld, V.; Ashur, I.; Scheer, H.; Baldridge, K. K.; Scherz, A. J. Am. Chem. Soc. 2000, 122, 3937-3944

(28) Noy, D.; Fiedor, L; Hartwich, G.; Scheer, H.; Scherz, A. J. Am. Chem. Soc. 1998, 120, 3684-3693.

(29) Yerushalmi, R.; Ashur, I.; Scherz, A. In Chlorophylls and Bacteriochlorophylls: Biochemistry, Biophysics and Biological Function; Scheer, H., Ed.; Kluwer Academic Publishers: Dordrecht, The Netherlands, in press.

(30) Hartwich, G.; Fiedor, L.; Simonin, I.; Cmiel, E.; Schafer, W.; Noy, D.; Scherz, A.; Scheer, H. J. Am. Chem. Soc. 1998, 120, 3675-3683.

(31) Hynninen, P. H. In Chemistry of Chlorophylls: Modifications; Scheer, H., Ed.; CRC: Boca Raton, 1991; pp 145-209.

(32) Hynninen, P. H.; Hyvarinen, K. J. Org. Chem. 2002, 67, 40554061 .

(33) Scherz, A.; Parson, W. W. Biochim. Biophys. Acta 1984, 766, 653665.

(34) (a) Wasielewski, M. R.; Svec, W. A. J. Org. Chem. 1980, 45, 19691974. (b) Diazald, MNNG, and Diazomethane Generators, Aldrich Technical Bulletin No. AL-180; Aldrich, Milwaukee, WI, 1993.

(35) Yerushalmi, R.; Noy, D.; Baldridge, K. K.; Scherz, A. J. Am. Chem Soc. 2002, 124, 8406-8415.

(36) Burfield, D. R.; Lee, K. H.; Smithers, R. H. J. Org. Chem. 1977, 42, 3060-3065.

(37) Burfield, D. R.; Smithers, R. H.; Tan, A. S. C. J. Org. Chem. 1981, $46,629-631$.

(38) Siegbahn, P. E. M. Adv. Chem. Phys. 1996, 93, 333-387.

(39) Frisch, M. J.; Trucks, G. W.; Schlegel, H. B.; Scuseria, G. E.; Robb, M. A.; Cheeseman, J. R.; Montgomery, J. A., Jr.; Vreven, T.; Kudin, K. N.; Burant, J. C.; Millam, J. M.; Iyengar, S. S.; Tomasi, J.; Barone, V.; Mennucci, B.; Cossi, M.; Scalmani, G.; Rega, N.; Petersson, G. A.; Nakatsuji, H.; Hada, M.; Ehara, M.; Toyota, K.; Fukuda, R.; Hasegawa, J. Ishida, M.; Nakajima, T.; Honda, Y.; Kitao, O.; Nakai, H.; Klene, M.; Li, X.; Knox, J. E.; Hratchian, H. P.; Cross, J. B.; Bakken, V.; Adamo, C.; Jaramillo, J.; Gomperts, R.; Stratmann, R. E.; Yazyev, O.; Austin, A. J.; Cammi, R.; Pomelli, C.; Ochterski, J. W.; Ayala, P. Y.; Morokuma, K.; Voth, G. A.; Salvador, P.; Dannenberg, J. J.; Zakrzewski, V. G.; Dapprich, S.; Daniels, A. D.; Strain, M. C.; Farkas, O.; Malick, D. K.; Rabuck, A. D.; Raghavachari, K.; Foresman, J. B.; Ortiz, J. V.; Cui, Q.; Baboul, A. G.; Clifford, S.; Cioslowski, J.; Stefanov, B. B.; Liu, G.; Liashenko, A.; Piskorz, P.; Komaromi, I.; Martin, R. L.; Fox, D. J.; Keith, T.; Al-Laham, M. A.; Peng, C. Y.; Nanayakkara, A.; Challacombe, M.; Gill, P. M. W. Johnson, B.; Chen, W.; Wong, M. W.; Gonzalez, C.; Pople, J. A. GAUSSIAN 03; Gaussian, Inc.: Wallingford CT, 2004.

(40) Reed, A. E.; Weinstock, R. B.; Weinhold, F. J. Chem. Phys. 1985, $83,735-746$

(41) Parr, R. G.; Yang, W. Density Functional Theory of Atoms and Molecules; Oxford University Press: New York, 1989.

(42) Becke, A. D. J. Chem. Phys. 1993, 98, 5648-5652.

(43) Lee, C.; Yang, W.; Parr, R. G. Phys. Rev. 1988, B37, 785-789.

(44) Boys, S. F.; Bernardi, F. Mol. Phys. 1970, 19, 553.

(45) Woo, K. G.; Sweigart, D. A. Inorg. Chem. 1993, 32, 4979-4981.

(46) Hobza, P.; Sponer, J.; Reschel, T. J. Comput. Chem. 1995, 16, $1315-1325$

(47) Fujii, A.; Ebata, T.; Mikami, N. J. Phys. Chem. A 2002, 106, 10124-10129.

(48) Chapman, D. M.; Muller-Dethlefs, K.; Peel, J. B. J. Chem. Phys. 1999, 111, 1955-1963. 